ORIGINAL ARTICLE

\title{
Injuries in elite motorcycle racing in Japan
}

\author{
Y Tomida, H Hirata, A Fukuda, M Tsujii, K Kato, K Fujisawa, A Uchida
}

Br J Sports Med 2005;39:508-511. doi: 10.1136/bjsm.2004.013722

See end of article for authors' affiliations

.....................

Correspondence to: Dr Hirata, Department of Orthopaedic Surgery, Mie University School of Medicine, 2-174

Edobashi, Tsu City 5148507, Japan; h-hirata@ clin.medic.mie-u.ac.jp

Accepted 23 November 2004
Objectives: To investigate the incidence and pattern of injuries, relative risks, and factors affecting incidence among elite motorcycle competitors in Japan.

Methods: A total of 117 elite motorcycle competitors including 36 road racers, 60 motocross racers, and 21 trial bike riders completed a questionnaire about injuries.

Results: Sixty major injuries (25 in road racing, 32 in motocross, and three in trial bike riding) were reported. The most common injuries were fractures (45), followed by ligament injuries (8), dislocations (5), and soft tissue injuries (2). The overall injury rate was 22.4 per 1000 hours, and the death rate was zero. There was no significant correlation between risk of injury and age, experience, or accumulated competition points.

Conclusions: Injury rates in competitions such as road racing and motocross are high, and therefore additional safety measures are needed to protect competitors from injury.
$T$ here is a general notion that high risk is an inherent aspect of motorcycle riding. A number of studies on motorcycle accidents have reported a high incidence of injuries, high injury severity scores, and high death rates. ${ }^{1-6}$ In motorcycle races, competitors are required to manoeuvre around obstacles and jockey for position along narrow winding tracks with hairpin turns and steep descents. Therefore intense competition appears to increase the chances of accident, even though competitors are skilled and experienced. To ensure that all competitors have the opportunity to compete as safely as possible, any organisation responsible for motorcycle competitions must set strict rules and regulations on the issue of licenses, race procedures, technical inspections, machine requirements, protective gear, etc. $^{78}$

However, the safety measures and conditions generally believed to reduce the risks may not always function as expected. There is even controversy about whether the use of a helmet, which would seem to be the most effective protective equipment, positively or negatively affects the incidence of serious injury or death. ${ }^{9}{ }^{10}$ Similarly, statistics from the US Department of Transportation National Highway Safety Administration (NHTSA) have clearly shown that a recent increase in older motorcyclists has resulted in a sharp increase in accidents and deaths. ${ }^{11}$ The implication is that apparently effective safety measures taken by organisers and competitors are not necessarily of use and may even have adverse effects. It is important to know the true risks of motorcycle sports and identify factors that positively or negatively contribute to injuries. We conducted a retrospective study of elite Japanese motorcycle competitors to examine injury rates, injury patterns, relative risks, and factors affecting injury incidence.

\section{METHODS}

Road racing, motocross, and trial bike riding are the three most popular motorcycle competitions in Japan. The Motorcycle Federation of Japan (MFJ) is the official organisation responsible for sanctioning all motorcycle races held in Japan and the issue of racing licenses. Riders are ranked according to ability and are assigned "international", "domestic", or "freshman" status. MFJ divides the country into four geographical areas and requires domestic and freshman competitors to earn points awarded in regional championships. Only riders who have earned at least 50 points in each category are promoted to the rank of international class A racers at the end of the season. They are then allowed to compete in the highest class of each category in the next season's national championships. Elite riders with an international class A rank account for less than $10 \%$ of road racers, $5 \%$ of motocross racers, and $3 \%$ of trial bike riders registered by MFJ. To retain the highest ranking, the riders are required to earn points in national championships at official courses across the country ( 11 road races, nine motocross races, seven trial bike competitions). Although any rider with an international class A ranking is eligible to ride at these events, few riders can afford to participate in races on a regular basis, other than those who have contracts with leading manufacturers such as Honda and Yamaha.

Table 1 shows the number of first class motorcycle riders in Japan and the points earned during the study period of March 2001-June 2002. The riders enrolled in this study earned a mean of 41.7 points (range 0-149) in road races, 45.1 points (range $0-264$ ) in motocross races, and 55.7 points (range 0-163) in trial biking. On the basis of these data, our sample represented truly elite motorcycle racers in Japan. Between March 2001 and June 2002, 117 elite motorcycle competitors ( 36 road racers, 60 motocross racers, and 21 trial bike riders) participated in the study by completing a questionnaire on injuries. A one on one method of interview was used to ensure that the questionnaire was completed fully. The data included age, race experience, points earned during the study period, number of competitions participated in, date of injury, injury diagnosis, mechanism of injury, whether the injury occurred during a practice or a race, protective gear used, and total time lost from participation.

The definition of injury was "an inability to train or compete in national championships". As other researchers have done, we categorised the severity of injury by time absent from race or practice. ${ }^{12-14}$ Injuries that interrupted participation for a period of less than a month were classified as minor and those necessitating absence for more than a month as major. In this study, only major injuries were considered.

Events sanctioned by MFJ are basically composed of a practice session, elimination rounds, and the final round. The composition is different in the three events (road racing: 
Table 1 Distribution of first class motorcycle riders according to points accumulated during the study period

\begin{tabular}{llllllll}
\hline & 0 & $1-50$ & $51-100$ & $101-150$ & $151-200$ & $>201$ & Total \\
\hline Road & 2361 & 85 & 19 & 13 & 2 & 1 & 2481 \\
Motocross & 305 & 51 & 11 & 9 & 4 & 5 & 385 \\
Trial & 57 & 27 & 12 & 4 & 1 & 0 & 101 \\
\hline
\end{tabular}

Table 2 Motorcycling injuries by anatomical area

\begin{tabular}{lcccc}
\hline & Road & Motocross & Trial & Total \\
\hline Neck & 0 & 1 & 0 & 1 \\
Trunk & 5 & 2 & 0 & 7 \\
Clavicle & 3 & 7 & 0 & 10 \\
Shoulder & 2 & 2 & 0 & 4 \\
Upper arm & 0 & 2 & 0 & 2 \\
Elbow & 0 & 0 & 1 & 1 \\
Forearm & 0 & 1 & 0 & 1 \\
Wrist & 1 & 5 & 2 & 8 \\
Hand/finger & 4 & 3 & 0 & 7 \\
Hip & 2 & 1 & 0 & 3 \\
Thigh & 1 & 0 & 0 & 1 \\
Knee & 3 & 3 & 0 & 6 \\
Lower leg & 1 & 1 & 0 & 2 \\
Ankle & 2 & 4 & 0 & 6 \\
Foot & 1 & 0 & 0 & 1 \\
Total & 25 & 32 & 3 & 60 \\
\hline & & & & \\
\hline
\end{tabular}

40 minute practice, $2 \times 20$ minute elimination rounds, and 40 minute final round; motocross: 10 minute practice round, 15 minute elimination round, and 30 minute final round; trial: four hour practice and five hour final round). We added up the practice and race times of all riders during the selected racing season to arrive at an approximate total practice and total race time for each competition. The sum of total practice and total race times was defined as total exposure time and used to establish an overall injury rate.

Injury rates were established by calculating the number of injuries per 1000 hours of each competition and separated into practice and race time. The results are reported as the mean (SD). Multivariate logistic regression was used to determine the effect of age, career, and accumulated points on injury rate. The $\chi^{2}$ test was used to compare injury rate among the three competitions and between practice and race in each competition. The level of significance was set at $\mathrm{p}<0.05$.

\section{RESULTS}

\section{Type and anatomical region of injuries}

Because we classified injury severity on the basis of time loss which was totally dependent on the rider's decision, even relatively minor injuries such as first or second degree sprain/ strain or soft tissue injuries may have been reported as severe injuries. Other injuries consisted of fractures (75\%), subluxation/dislocation $(10 \%)$, and rupture of tendons or
Table 4 Overall injury rates of each competition

\begin{tabular}{lccc}
\hline & Injury & Exposure time & Injury rate \\
\hline Road & 25 & 702 & 35.6 \\
Motocross & 32 & 650 & 49.2 \\
Trial & 3 & 1323 & 2.3 \\
Total & 60 & 2675 & 22.4 \\
\hline & &
\end{tabular}

Table 5 Comparison of the injury rate among the three competitions

\begin{tabular}{llll}
\hline & Road & Motocross & Trial \\
\hline Road & - & NS & $<0.0001$ \\
Motocross & - & - & 0.0026 \\
Trial & - & - & - \\
\hline
\end{tabular}

Values are $p$ values $\left(\chi^{2}\right.$ test $)$

ligaments (13\%). No serious injuries such as brain damage or internal injury to the chest or abdomen were reported, and the death rate was zero.

Table 2 shows the most common sites of injury for riders of each competition during the period investigated. Shoulder and hand injuries occurred most often in road racing and motocross, and the forearm including the wrist was the most common injury site in trial biking. Table 3 shows the types of injury in each competition.

\section{Injury rate, relative risk, and effect of competition intensity}

Of the 60 reported injuries, 18 involved collisions with other motorcycles and the rest occurred as result of single vehicle accidents. Fifty four injuries occurred while riders were negotiating curves, bumps, or steep slopes. Table 4 shows injury rates for each competition calculated with the above formula. Our sample of 117 competitors had a total exposure time of 2675 hours, giving an overall injury rate of 22.4 per 1000 hours.

As shown in table 5, the injury rate in trial biking was significantly lower than in the other two competitions. So, we assigned trial biking as the baseline for comparison, which yielded a 15.5 times higher relative risk for road racing and 21.4 times higher relative risk for motocross.

Table 3 Types of injury in motorcycle competition

\begin{tabular}{llllll}
\hline & Fracture & Ligament injury & Dislocation & Contusion & Total \\
\hline Road & 17 & 3 & 3 & 2 & 25 \\
Motocross & 26 & 4 & 2 & 0 & 32 \\
Trial & 2 & 1 & 0 & 0 & 3 \\
Total & 45 & 8 & 5 & 2 & 60 \\
\hline
\end{tabular}




\begin{tabular}{|c|c|c|c|}
\hline & Injury & Exposure time & Injury rate \\
\hline \multicolumn{4}{|l|}{ Road } \\
\hline Practice & 13 & 234 & 55.6 \\
\hline Race & 12 & 468 & 25.6 \\
\hline Total & 25 & 702 & 35.6 \\
\hline \multicolumn{4}{|l|}{ Motocross } \\
\hline Practice & 11 & 90 & 122.2 \\
\hline Race & 22 & 560 & 39.3 \\
\hline Total & 33 & 650 & 49.2 \\
\hline \multicolumn{4}{|l|}{ Trial } \\
\hline Practice & 1 & 588 & 1.7 \\
\hline Race & 2 & 735 & 2.7 \\
\hline Total & 3 & 1323 & 2.3 \\
\hline
\end{tabular}

To assess the effect of competition intensity on injury rate, we compared injury incidence in races and practice sessions (table 6). Contrary to expectation, in road racing and motocross, injury rates during practice sessions were noticeably higher than during races, although the $\chi^{2}$ test confirmed the difference only in motocross (table 7 ). In contrast, in the case of trial biking, injury rate during races was 1.6 times higher than during practice.

\section{Effect of age, career, and points obtained}

We examined the role in injury mechanism of age, experience, and ranking in each competition. As shown in table 8, neither age nor experience of the riders correlated with injury in any of the three competitions. Similarly, accumulated points, which should reflect the rider's skill, did not show any relation to injury.

\section{DISCUSSION}

The measurement or assessment of injury severity in motorcycle competitors has several limitations. Professional or equivalent riders compete year round, unless they have injuries that are sufficiently severe to keep them away from

\begin{tabular}{ll}
$\begin{array}{l}\text { Table } 7 \text { Comparison of injury rate between } \\
\text { practice and race in each competition using the } \\
\chi^{2} \text { test }\end{array}$ \\
\hline & $\mathrm{p}$ Value \\
\hline Road race & NS \\
Motocross & 0.0245 \\
Trial & NS \\
\hline
\end{tabular}

competition. They tend to participate in races even with severe injuries such as fractures of the clavicle or fibula. In contrast, amateur riders may skip a race for less severe injuries. Nevertheless, our data clearly show that, although the overall injury rate of motorcycle competition (22.4 per 1000 hours) was 3.6 times higher than that of major league soccer players, ${ }^{13}$ serious injuries to brain, spinal cord, chest, or abdomen were extremely rare. This is in sharp contrast with ordinary motorcycle users whose fatality rate has been reported by NHTSA to be 14 times higher than that of car users. ${ }^{11}$ Horner and O'Brien, ${ }^{15}$ who compared motorcycle injuries that occurred on a race track with those of car races conducted on road circuits for the same two year period, reported an equally low incidence of serious injuries and deaths.

According to NHTSA, most deaths of motorcyclists involved a crash with another vehicle or collision with fixed objects, and more than $85 \%$ occurred on rural roads with no road markings, especially when riders were negotiating curves. ${ }^{11}$ These critical factors for motorcyclist injury are absent in motorcycle competitions. All vehicles on the race track are travelling in the same direction. There are no fixed objects on or around the course, and sand banks or cushions are placed at every corner to decelerate vehicles out of control and thrown riders. Varley et $a l^{16}$ conducted a prospective study of injury patterns in motorcycle road races on the Isle of Man, where many of the public highways form part of the circuit. They found a casualty rate 15 times higher and a death rate 87 times higher than for motorcyclists in the United Kingdom. The report of Varley et al and the high injury rates shown in this study suggest that injury severity and fatality rate would have been much higher in Japan if MFJ had not intervened appropriately. This speculation is also supported by the fact that most accidents occurred when great vehicle manoeuvrability was required. In our study, it appears that better field and safety regulations did lower the incidence of serious injuries but did not reduce the injury rate in this highly competitive sport.

This study clearly shows that trial biking is a much safer competition with a significantly lower injury rate than the other two forms of motorcycle racing. As mentioned above, the relative risk of motocross is 21.4 times higher and road race is 15.5 times higher than trial biking. Trial biking is safe even compared with professional soccer with a relative risk of 0.38 . We hypothesise that its relative safety comes from the inherent nature of the event. Unlike most other motorcycle sports, trial biking is not a race. It is a sport of balance, skill, and concentration. Competitors ride, one at a time, over an obstacle course of boulders, streams, steep hill climbs, logs, drop offs, etc. Low speeds and no opportunity of collision

Table 8 Effect on injury of age, career, and points obtained

\begin{tabular}{|c|c|c|c|c|c|c|c|c|}
\hline \multirow[b]{2}{*}{ Age lyears } & \multicolumn{2}{|l|}{ Road } & \multicolumn{2}{|c|}{ Motocross } & \multicolumn{2}{|l|}{ Trial } & \multicolumn{2}{|l|}{ Total } \\
\hline & & & & & & & & \\
\hline Injury & + & - & + & - & + & - & + & - \\
\hline Mean & 27.0 & 28.2 & 20.8 & 22.9 & 19.5 & 22.5 & 22.7 & 24.7 \\
\hline SD & 1.2 & 4.0 & 2.7 & 3.7 & 2.1 & 5.9 & 3.4 & 5.0 \\
\hline $\mathrm{p}$ Value & NS & & NS & & NS & & NS & \\
\hline \multicolumn{9}{|c|}{ Experience/career (years) } \\
\hline Injury & + & - & + & - & + & - & + & - \\
\hline Mean & 7.2 & 9.2 & 11.6 & 13.5 & 10.0 & 8.8 & 10.8 & 10.9 \\
\hline SD & 2.6 & 3.7 & 2.9 & 4.0 & 2.8 & 4.1 & 3.2 & 4.5 \\
\hline$p$ Value & NS & & NS & & NS & & NS & \\
\hline \multicolumn{9}{|c|}{ Points obtained } \\
\hline Injury & + & - & + & - & + & - & + & - \\
\hline Mean & 30.6 & 43.6 & 33.2 & 53.6 & 78.0 & 53.3 & 35.6 & 50.0 \\
\hline SD & 32.8 & 56.2 & 65.8 & 73.6 & 38.2 & 53.9 & 60.5 & 63.0 \\
\hline $\mathrm{p}$ Value & NS & & NS & & NS & & NS & \\
\hline
\end{tabular}


What is already known on this topic

Few articles have dealt with injuries in motorcycle racing.

\section{What this study adds}

We found that serious injuries are rare. However, injury rate in road racing and motocross is high. In contrast, trial biking was found to be safe. Injuries occurred significantly more often during practices than during races in the former two competitions.

with other competitors are likely to make the competition fairly safe.

The difference in anatomical region of injury also reflects the nature of the competition. As injuries usually occur when riders are thrown from the vehicle in road racing and motocross, most injuries are to the upper extremities, including the shoulder girdle. In contrast, trial riders are usually injured when they fall from a height, resulting in wrist injuries.

We examined the role of competition intensity in injury incidence by comparing injury rates in practice sessions and races. Before the study, we expected to find that accidental injuries usually occur during the final rounds followed by the elimination rounds because of the increasing intensity of competition. However, the injury rate in road racing and motocross is significantly higher in practice sessions than in races. This indicates that competitors ride more aggressively in practices than was thought to acquire better start positions. One possible reason for this contradictory result lies in the mindset of the racers and engineers. To know the limitation of their vehicle before the race, they may take more risks during practice sessions.

Although Horner and $\mathrm{O}^{\prime} \mathrm{Brien}^{15}$ claim that inexperienced riders are more likely to be involved in accidents, we found little correlation between injury rate and points accumulated or experience. Superiority in skill and experience may be offset by the inherent intensity associated with racing.

We were unable to evaluate the role of protective gear. MFJ strictly requires and checks the use of protective equipment, and no competitor sustained injuries that could be attributed to the lack of such equipment or its inappropriate use. It had been supposed that death rates are significantly lower in countries that do not have strict laws on the use of motorcycle helmets, ${ }^{10}$ but Branas and Knudson ${ }^{9}$ showed the exact opposite after controlling for other factors associated with deaths of motorcycle riders. Recent investigations on the usefulness of helmets also showed that, although the helmet is effective in protecting the head, it does not reduce the overall death rate. ${ }^{17}{ }^{18}$ With these reports in mind, we strongly believe that wearing a full face type of helmet is worth while.
However, considering the lack of reliable information on other protective gear and the significant injury rate in high speed motorcycle racing, it is extremely important to continue research and development of protective equipment.

In conclusion, this study shows that in Japan both deaths and serious injuries are very rare in motorcycle competitions probably thanks to appropriate interventions by MFJ. Although it is logical to assume that the excellent technique and depth of experience of elite competitors would result in fewer accidents and injuries, statistical analysis shows that these factors contribute less than expected. Therefore improvement of other factors such as stricter safety rules for practice sessions and the development of more effective safety gear are key to reducing the injury rate in high speed competitions.

\section{Authors' affiliations}

Y Tomida, K Kato, K Fujisawa, Department of Orthopaedic Surgery, Suzuka Kaisei General Hospital, Tsu City, Japan

H Hirata, A Fukuda, M Tsujii, A Uchida, Department of Orthopaedic Surgery, Mie University School of Medicine, Tsu City, Japan

Competing interests: none declared

\section{REFERENCES}

1 Kraus JF, Peek-Asa C, Cryer HG. Incidence, severity, and patterns of intrathoracic and intra-abdominal injuries in motorcycle crashes. J Trauma 2002;52:548-53.

2 Langley J, Mullin B, Jackson R, et al. Motorcycle engine size and risk of moderate to fatal injury from a motorcycle crash. Accid Anal Prev 2000;32:659-63.

3 Peek C, Braver ER, Shen $\mathrm{H}$, et al. Lower extremity injuries from motorcycle crashes: a common cause of preventable injury. J Trauma 1994;37:358-64.

4 Sood S. Survey of factors influencing injury among riders involved in motorized two-wheeler accidents in India: a prospective study of 302 cases. J Trauma 1988;28:530-4.

5 Stella J, Cooke C, Sprivulis P. Most head injury related motorcycle crash deaths are related to poor riding practices. Emerg Med (Fremantle) 2002; 14:58-61

6 Zettas JP, Zettas P, Thanasophon B. Injury patterns in motorcycle accidents. J Trauma 1979;19:833-6.

7 FIM (Fèdèration Internationale Motocyclisme) 2003 race rules. http:// www.fim.ch/en/ (accessed 11 May 2005).

8 MFJ 2003 race rules. http://www.mfi.or.jp/ (accessed 11 May 2005).

9 Branas CC, Knudson MM. Helmet laws and motorcycle rider death rates. Accid Anal Prev 2001;33:641-8.

10 United States Department of Transportation National Highway Traffic Safety Administration. http://www.nhtsa.dot.gov/ (accessed 11 May 2005).

11 National Highway Traffic Safety Administration. Recent trends in motorcycle fatalities. Ann Emerg Med 2002;39:195-6.

12 Engstrom B, Johansson C, Tornkvist H. Soccer injuries among elite female players. Am J Sports Med 1991;19:372-5.

13 Morgan BE, Oberlander MA. An examination of injuries in major league soccer. The inaugural season. Am J Sports Med 2001;29:426-30.

14 Nielsen AB, Yde J. Epidemiology of acute knee injuries: a prospective hospital investigation. J Trauma 1991;31:1644-8.

15 Horner $\mathrm{CH}, \mathrm{O}^{\prime} \mathrm{Brien} \mathrm{AA}$. Motorcycle racing injuries on track and road circuits in Ireland. Br J Sports Med 1986;20:157-8.

16 Varley GW, Spencer-Jones R, Thomas P, et al. Injury patterns in motorcycle road racers: experience on the Isle of Man 1989-1991. Injury 1993;24:443-6.

17 Auman KM, Kufera JA, Ballesteros MF, et al. Autopsy study of motorcyclist fatalities: the effect of the 1992 Maryland motorcycle helmet use law. Am J Public Health 2002;92:1352-5.

18 Hotz GA, Cohn SM, Popkin C, et al. The impact of a repealed motorcycle helmet law in Miami-Dade County. J Trauma 2002;52:469-74. 